\title{
Fiber laser welding of AA 5754 in the double lap-joint configuration: process development, mechanical characterization, and monitoring
}

\author{
Matteo Garavaglia $^{1}$ - Ali Gökhan Demir ${ }^{1}$ (D) Stefano Zarini ${ }^{2} \cdot$ Brian M. Victor $^{3} \cdot$ Barbara Previtali $^{1}$
}

Received: 22 April 2020 / Accepted: 20 September 2020 / Published online: 15 October 2020

(C) The Author(s) 2020

\begin{abstract}
Aluminum alloys are widely spread in many industrial sectors due to their desirable characteristics as low density, good formability, high specific strength, and good resistance to corrosion. Autogenous laser welding is a technology that enables the use of these materials in the industrial process due to its high repeatability, reliability, and ease of automatization. In particular, in automotive applications, Al-alloys are welded in lap-joint configurations with more than 2 layers of material. The welding condition should be monitored in order to detect the complete penetration, hence guaranteeing the appropriate weld resistance. The use of non-invasive and coaxial monitoring solutions is highly desirable for the identification of weld defects during the process. This study investigates an autogenous laser welding process and monitoring in the double lap-joint configuration of sheets of AA 5754. First, the process parameters are investigated to identify the geometrical and mechanical characteristics of the resultant welding seams at different process conditions. The employed high-brilliance $3 \mathrm{~kW}$ fiber laser provided the possibility of reading the back-reflected light signal from an internal photodiode. The capability of this signal to be used as a non-invasive, coaxial, and remote monitoring system in order to predict the process outcome was tested. In the experiments the back-reflected light intensity could be correlated to the weld seam width at the second interface, as well as the strength of the joint to shear. Finally, the monitoring signal behavior was demonstrated under simulated weld defect conditions. The results show that weld anomalies such as lack of penetration, misalignment, and gap formation can be sensed through the monitoring approach.
\end{abstract}

Keywords Autogenous keyhole welding $\cdot$ Automotive $\cdot$ Body in white $\cdot$ Shear strength $\cdot$ Back reflection

\section{Introduction}

The relevance of aluminum alloys in industrial applications has grown in the last years due to the necessity of lightweight design of mechanical components. In particular, in the automotive sector electric vehicles are gaining importance [1], and aluminum alloys are the first choice as lightweight materials for many components like car bodies and batteries casings [2-5]. Concerning the assembly of aluminum alloy components, laser beam welding has become an established solution

Ali Gökhan Demir

aligokhan.demir@polimi.it

1 Department of Mechanical Engineering, Politecnico di Milano, Via La Masa 1, 20156 Milan, Italy

2 Optoprim S.r.l., Via Carlo Rota 37, 20900 Monza, Italy

3 nLight, Inc., 5408 NE 88th Street, Building E, Vancouver, WA 98665, USA in the industry. Indeed, the high energy intensity of the laser beam allows to deliver a low overall heat input fulfilling the welding operation with reduced thermal damage to the surrounding material [6]. This allows the achievement of a fine weld seam with narrow heat affected zone and limited thermal distortion with respect to alternative processes like tungsten inert gas (TIG) or metal inert gas (MIG) welding. However, the high optical reflectivity of aluminum and its alloys has been for years the major obstacle to achieve a stable process in laser welding. The optical absorptivity of aluminum greatly improves at $1 \mu \mathrm{m}$ wavelength of solid state Nd:YAG lasers compared with $10 \mu \mathrm{m}$ of the $\mathrm{CO}_{2}$ lasers [7]. Due to the optical absorptivity, the use of $\mathrm{CO}_{2}$ lasers for welding $\mathrm{Al}$-alloys was not industrially feasible. The use of solid state Nd:YAG lasers opened up the possibility of laser welding Al-alloys. However, they have been characterized by lower beam quality, and high peak power could be reached only in pulsed wave mode. The wider use of high power Yb:glass fiber lasers operating at $1 \mu \mathrm{m}$ wavelength provided higher brilliance at continuous wave $(\mathrm{CW})$ power emission enabling deep 
welding operations reliable also for highly reflective materials such as Al-alloys. The high intensity of the fiber laser beam overcomes the high reflectivity of the Al-alloy, producing molten material, which further increases the optical absorption creating the keyhole. Welding in keyhole regime has the advantage to create a weld seam with high aspect ratio (depth over width), limited heat affected zone, higher penetration, and good mechanical properties. On the other hand, the generated keyhole cavity is affected by instability which can lead to various defects $[8,9]$. The presence of metallic vapors that have an important role in sustaining the cavity is also a source of turbulent flow of molten material that can cause spatter and pore formation [9]. Moreover, the presence of low vaporization temperature alloying elements in aluminum alloys (e.g., $\mathrm{Mg}$ and $\mathrm{Zn}$ ) increases these phenomena and has the consequence of modifying the chemical composition of the alloy in the weld region with detrimental effects on the mechanical properties $[8,10,11]$. The selection of the process parameters is evidently required to achieve welds with the desired mechanical properties. On the other hand, the process should be robust against variations occurring in industrial environment. For instance in automotive industry, the welding of Al-alloy plates in a lap-joint configuration may require dedicated fixtures. Misalignment, gap formation, and contamination on the surface can cause changes in the welding configuration resulting in insufficient mechanical properties.

The use of laser welding of Al-alloys in automotive industry has been applied in different configurations. The use of autogenous laser welding is highly advantageous especially for fillet [12] and lap-joint configurations [13], which can be applied both remotely [14] and in proximity [13]. A certain type of joints used in automotive sector is the double-lap. Double-lap joint allows to stack multiple layers of sheet material, allowing for a reduction in the number of joints to be produced. Double lap-joint welds are applied to car bodies and battery casings [15]. The use of double-lap joint is also beneficial for design and production of lightweight sandwich panels [16]. However, in the presence of two interfaces between the three layers of sheet material the gap formation possibility increases. The double-lap joint provides the flexibility of joining three different parts in a simple and single joint, reducing the alignment issues and the difficulties concerning gap formation. Indeed, the use of other configurations such as a combined butt and T-joint would be much more difficult to align. As a matter of fact the double-lap joint configuration is enabled by a deep penetration welding process such as laser welding. The keyhole welding mode allows the laser beam to penetrate through the layers of material autogenously with limited heat affected zone. Arc based welding methods would induce a larger heat affected zone. Friction stir welding is also commonly applied to reduce the heat damage on the Al-alloys, while the autogenous laser beam provides higher flexibility in terms of the accessibility of the welding zone. Hence, the full penetration in laser welding becomes desirable also for ensuring the complete weld between all different layers. In industrial practice a fully penetrated seam is also used as a qualitative indicator to a complete weld process where the connection between all layers is ensured. Indeed, a full penetration weld can also be defected, where more reliable solutions to reveal the weld quality during the process are required.

From this point of view, inline monitoring approaches are appealing to indicate the process stability. Various sensors are exploited for this purpose [17]. Acoustic [18], electrical [19], and optic sensors have been proposed in literature. The optical sensors are highly flexible as they can be used to detect the process radiation, the fluctuations in the back-reflected laser light, or employ a probe beam to quantify the weld characteristics. Radiation intensity detectors like photodiodes offer high temporal resolution and with appropriate filter can detect light at different wavelength, such as visible light, laser reflected radiation, or infrared [20,21]. Multiple photodiodes can be combined to achieve improved selectivity of wavelength while maintaining high temporal resolution [22]. Pyrometers offer a punctual measurement of the temperature in the process zone of interest, usually the melt pool [23]. Spectrometers allow the detection of the whole spectrum of radiation with good temporal resolution [24]. Low-coherence tomography can also be employed to detect the weld depth $[25,26]$, while its application is cumbersome for full penetration welds. When higher spatial resolution is required, CCD (charged-coupled device) or CMOS (complementary metaloxide-semiconductor) cameras [27] are widely adopted. The use of thermal [28] and hyperspectral [29] cameras has also been reported to estimate the weld pool temperatures. These devices offer the possibility to have a comprehension of the process through images instead of simple signals. However, their applicability may be limited to the data to be transferred, analyzed, and stored. Concerning the different options, it is more desirable to choose a monitoring option that is not invasive on the machine architecture, easy to integrate, and operate. Indeed, the fiber laser sources can embed such sensors to the source itself [30]. The process fiber can be employed to retract the process emission and the back reflected laser light. The signal can be resolved in emission spectrum by spectroscopy, or intensity fluctuations can be analyzed via simple photodiodes. By simulating a series of expected weld defects, the signals can be sampled prior to the production. The comparison of welding signals during the production can be an effective way of process monitoring. Concerning the Al-alloys, the laser back reflected light is a key parameter that can be analyzed [31]. Indeed, fluctuations in the back reflected laser light intensity can be linked to lower energy absorption [32], hence, an instable weld.

In this work, laser welding of AA5754 Al-alloy in double lap-joint configuration is investigated. A novel fiber laser 
source with integrated in-source back reflection monitoring capability was employed. Experiments were carried out to assess the effect of the process parameters on weld geometry and strength. Monitoring signals were acquired and correlated to the weld seam geometry. Moreover, the mechanical strength at the second interface of the double-lap joint, which is the most critical part of the joint, could be correlated to the monitoring signal. Finally, defected conditions expected to occur in industrial application were simulated acquiring the monitoring signals showing the potential of the monitoring approach for detecting the weld defects.

\section{Materials and methods}

\subsection{Materials}

AA5754 (AlMg3) sheets ( $1 \mathrm{~mm}$ thick) were used throughout the work. The features of the alloy are good weldability and formability together with good mechanical properties and good resistance to corrosion. Its fields of applications are shipbuilding, food processing equipment, welded chemical, and nuclear structures [33]. The AA5754 alloy is commonly used in automotive applications. In particular, it is employed for producing car body parts. Recently, its use has been also extended to the battery casings. In both of the uses, double-lap joint configurations can be employed. The nominal UTS of the material is in the range of $220-270 \mathrm{MPa}$. The chemical composition of the alloy is shown in Table 1.

\subsection{Laser welding system}

The laser source was a high-brilliance 3-kW fiber laser (nLIGHT alta). The laser radiation is delivered to the process head through a fiber that has a core diameter of $100 \mu \mathrm{m}$. The laser is specifically designed to safely process highly reflective materials such as copper or aluminum. Internal hardwarebased back reflection protection removes back-reflected light from the fiber and safely dissipates it as heat.

The process head was configured with a $75-\mathrm{mm}$ collimating and a 200-mm focal lens (Laser Mechanisms FiberMINI). In the current configuration, a theoretical spot size of $267 \mu \mathrm{m}$ on the focal plane was produced. The calculated Rayleigh length of the optical configuration was $7.43 \mathrm{~mm}$. The weld head was positioned with a numerically controlled 3 -axis

Table 1 Nominal chemical composition of AA 5754

\begin{tabular}{llllllllll}
\hline Element & $\mathrm{Si}$ & $\mathrm{Fe}$ & $\mathrm{Cu}$ & $\mathrm{Mn}$ & $\mathrm{Mg}$ & $\mathrm{Cr}$ & $\mathrm{Zn}$ & $\mathrm{Ti}$ & Others \\
\hline $\mathrm{Wt} \%$ & 0.40 & 0.40 & 0.10 & 0.50 & $2.60-3.60$ & 0.30 & 0.20 & 0.15 & 0.05 \\
\hline
\end{tabular}

cartesian system. The main specifications of the system are shown in Table 2.

\subsection{Monitoring system}

The laser source has an internal photodiode that detects the reflected laser light coming from the process emission back into the fiber [34]. The photodiode sensitivity range is between 400 and $1100 \mathrm{~nm}$ corresponding to the back reflected laser light intensity, as well as the plasma and plume emission in the visible range. The read-out of the photodiode signal is available from the control interface connectors. The back reflection (BR) analog output was connected with a shielded wire to a digital oscilloscope (Tektronix TBS-1042). The signal was acquired with $1 \mathrm{kHz}$ sampling rate, and the acquisition was triggered by the rising signal.

The BR signal was collected throughout the whole experimental campaign during the production of all the specimens. The raw signal is cut to isolate only the points that refer to the process, and time scale is adjusted. The stationary part of process, after the acceleration and before the deceleration of the axes, was considered for the evaluation. A time interval of $0.2 \mathrm{~s}$ of the central part of each signal is isolated to evaluate mean and standard deviation. Figure 1 shows the various stages involved in the signal analysis.

\subsection{Material characterization}

\subsubsection{Weld seam cross-section characteristics}

Cross-sections were prepared at the middle of each seam. Samples were mounted, ground, and polished for metallographic analysis. Optical microscopy images were taken, which were later used to measure the following weld seam characteristics as schematically shown in Fig. 2. An image processing software was employed for the measurements (ImageJ). The width of the weld seam was measured at the first $\left(w_{\text {int }, 1}\right)$ and the second interfaces $\left(w_{\text {int, } 2}\right)$. For shear

Table 2 The main characteristics of the laser system

\begin{tabular}{lll}
\hline Parameter & Symbol & Value \\
\hline Emission wavelength & $\lambda$ & $1080 \mathrm{~nm}$ \\
CW emission power & $P$ & $3000 \mathrm{~W}$ \\
Beam quality & $M^{2}$ & 6.98 \\
Beam parameter product & $\mathrm{BPP}$ & $2.4 \mathrm{~mm} \times \mathrm{mrad}$ \\
Collimation length & $f_{\text {col }}$ & $75 \mathrm{~mm}$ \\
Focal length & $f_{\text {foc }}$ & $200 \mathrm{~mm}$ \\
Fiber core diameter & $\Phi_{\text {core }}$ & $100 \mu \mathrm{m}$ \\
Focal spot diameter & $d_{0}$ & $267 \mu \mathrm{m}$ \\
Divergence angle & $\theta$ & $0.036 \mathrm{rad}$ \\
\hline
\end{tabular}



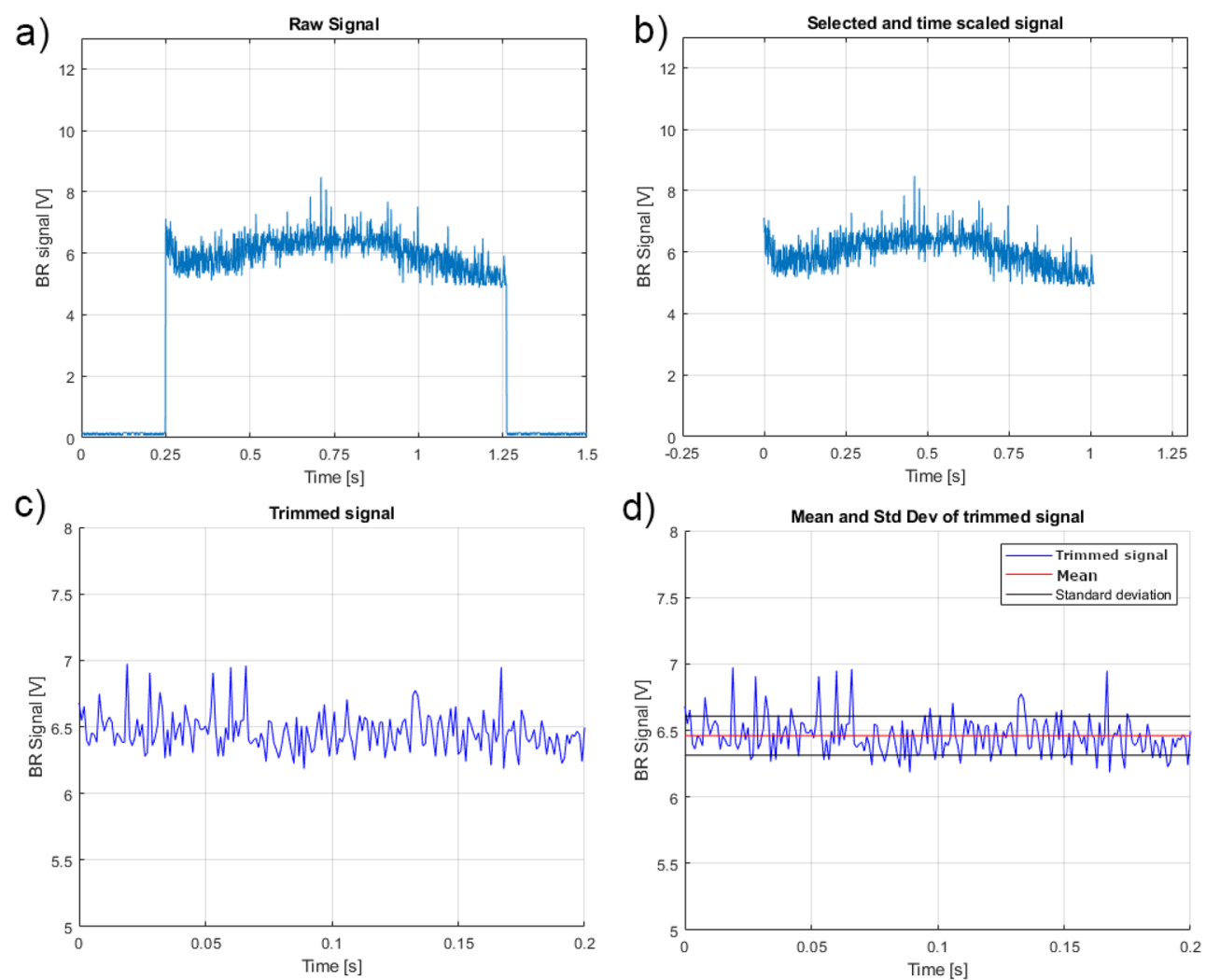

Fig. 1 a Example of a raw signal. b Selected and time scaled process signal. $\mathbf{c}$ Central part of the signal related to the stable process. d Stable process signal with highlighted mean value and standard deviation

strength these widths are important as they determine the longitudinal section that withstands the load. The penetration depth $\left(d_{p}\right)$ was measured, which indicates whether the weld depth is sufficient or not for the double-lap joint configuration. The maximum value of penetration depth is $3 \mathrm{~mm}$ for complete penetration cases, even if excess material drops out from the bottom side of the plates. The area of the weld seam $\left(A_{w}\right)$ was measured, which is an overall indicator to the amount or material melted in the cross-section. The total area of the pores was measured to account for this weld defect $\left(A_{p}\right)$. In order to measure the pore areas, the images were binarized, where bright regions corresponded to the pores. The sum of the pore areas was calculated from the binarized images.

\subsubsection{Tensile shear tests}

The tests and the specimens were developed on the base of the standards ASTM D3528-96 and BS EN ISO 12996:2013. The aim was to test the strength of each of the two weld interfaces, the one between the first and the second layers and the one between the second and the third layers. Therefore, for each process parameter the shear strength at the first and second interfaces was evaluated as depicted in Fig. 3. In the tensile shear tests, the determination of the strength is difficult, since the exact section that bears the load is not easily identifiable. Maintaining pure shear action on the weld seam is also experimentally very difficult. Therefore, conventionally, the test results are reported as a function of the force and compared with the resistance of the material without any weld seam. Hence, the resistance of the base material was also evaluated by the tensile testing of the single Alalloy sheet without a weld seam.

\section{Experimental plan}

Autogenous laser welding of the AA5754 sheets in double lap-joint (three layers) was studied. The present joint can be commonly processed in remote welding configuration. Although the processing head was for proximity welding

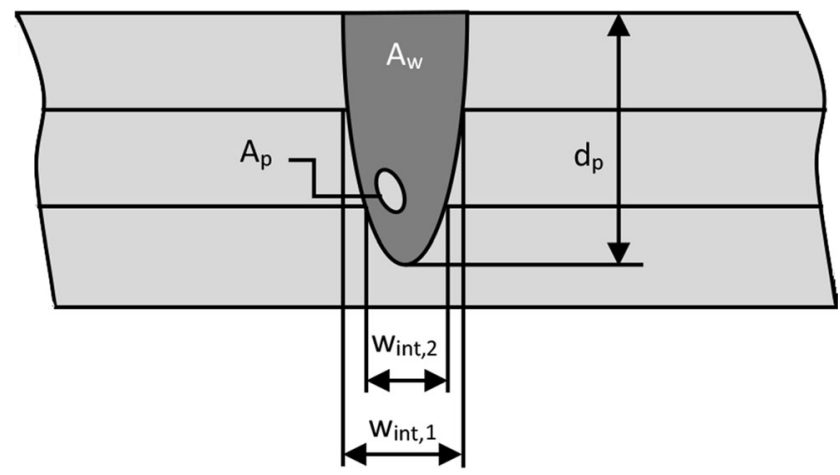

Fig. 2 Schematic description of the measured weld seam characteristics 
Fig. 3 Schematic representation of the performed tests and the image of a sample during the tensile shear test

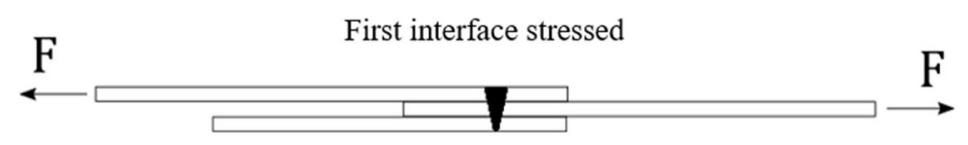

Second interface stressed

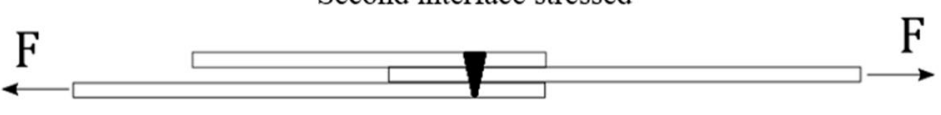

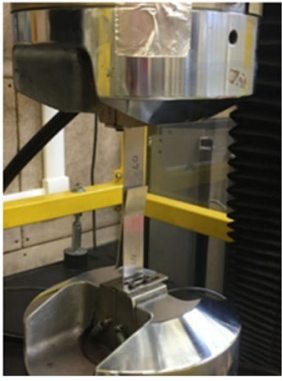

applications, the conditions in terms of spot size and shielding gas were chosen similarly to achieve equivalent conditions. In the explored welding application, the main aim is to achieve a highly productive process, where full penetration is desired to ensure the welding of all the three sheet layers. Excessive pore formation, undercuts, and dropouts should be avoided.

The experimental plan is designed starting from the process feasibility window extracted in a preliminary analysis [31]. Laser power was fixed to the maximum available at $3 \mathrm{~kW}$. A full factorial experimental plan was executed varying the welding speed and the focal position. The welding speed was varied from 1.2 to $14.2 \mathrm{~m} / \mathrm{min}$, while the focal positions was varied at $0,-2$, and $-4 \mathrm{~mm}$ with respect to the workpiece surface, where negative value correspond to the focal position below the surface. The corresponding beam diameters at $-2 \mathrm{~mm}$ and $-4 \mathrm{~mm}$ focal positions were $277 \mu \mathrm{m}$ and $303 \mu \mathrm{m}$, respectively. No shielding gas was employed during the process as similarly to the remote welding applications. For all combinations, 3 replications for characterizing the cross section and 2 for samples devoted to tensile shear tests were executed with the dimensions depicted in Fig. 4a and b. The sheets to be welded were fixed in the double lap-joint configuration using a mechanical clamping system shown in Fig. 4c. The sheets were placed inside the clamps from both ends, and the clamps were closed by means of two screws allowing to avoid gap formation. In order to acquire cross section images of the weld seams, sample size was $120 \times 30 \mathrm{~mm}$. In order to test the mechanical properties, three sheets with dimension of $150 \times 120 \mathrm{~mm}$ with an overlap length of $50 \mathrm{~mm}$ were welded. These specimens were then cut to a width of $25 \mathrm{~mm}$ in the central part of the seam where the process is stationary by abrasive water jetting. The weld seam length was $100 \mathrm{~mm}$ for all specimens Table 3 shows a summary of the experimental conditions.

\section{Results and discussion}

\subsection{Geometrical characteristics}

Figure 5 shows representative images for each investigated condition of process parameters. Within the experimented conditions, distinct welding conditions were achieved. At higher welding speeds and defocused conditions, the weld penetration was lost and high levels of porosity were observed. On the other extreme with low welding speed and with $f=0 \mathrm{~mm}$ a high level of drop-out was visible. At $11.2 \mathrm{~m} / \mathrm{min}$ with $f=0 \mathrm{~mm}$ and $f=-2 \mathrm{~mm}$, partial penetration welds could be achieved. While they can be of esthetic interest, for automotive applications, full penetration is desirable to ensure that the double-lap joint weld is fulfilled. At lower speeds the weld seam started to generate drop-out at the bottom side and a partial undercut on the top side. It can be expected that with lower speeds the melt pool remains at high temperatures for a prolonged duration, allowing the material flow towards the bottom due to the gravitation and generating the drop-out. A prolonged exposure to the laser beam is also expected to remove material by vaporization from the top side, hence, generating the undercuts.

Figure 6 shows the measured values of the seam width at the first and second interfaces. It can be seen that an increase of the weld speed generates a rapid decay in the weld width. While the focal distance does not appear to have a significant effect between $f=0 \mathrm{~mm}$ and $f=-2 \mathrm{~mm}$, a further increase at $f=-4 \mathrm{~mm}$ results in the lack of penetration at higher welding speeds. Indeed, with the loss of penetration to the third layer of sheets, the seam width is not measurable. The loss of penetration can be attributed to the beam irradiance on the top surface. With a more defocused beam and hence a smaller irradiance, the process becomes more sensitive to the weld speed variations.

Figure 7 shows the weld and pore areas as a function of the process parameters. The weld area corresponds to the amount of melted material, which is strongly correlated to the delivered amount of energy. Due to the fact that in the experimental campaign the power level was kept constant, the energy input relies on the weld speed. Accordingly, the weld area appears

Table 3 Fixed and varied parameter levels employed in the experimental campaign

\begin{tabular}{ll}
\hline $\begin{array}{l}\text { Fixed parameters } \\
\text { Power }\end{array}$ & Values \\
& $3000 \mathrm{~W}$ \\
Variable parameters & Values \\
Welding speed, $v$ & $2.2,5.2,8.2,11.2,14.2 \mathrm{~m} / \mathrm{min}$ \\
Focal position, $f$ & $0,-2,-4 \mathrm{~mm}$ \\
\hline
\end{tabular}




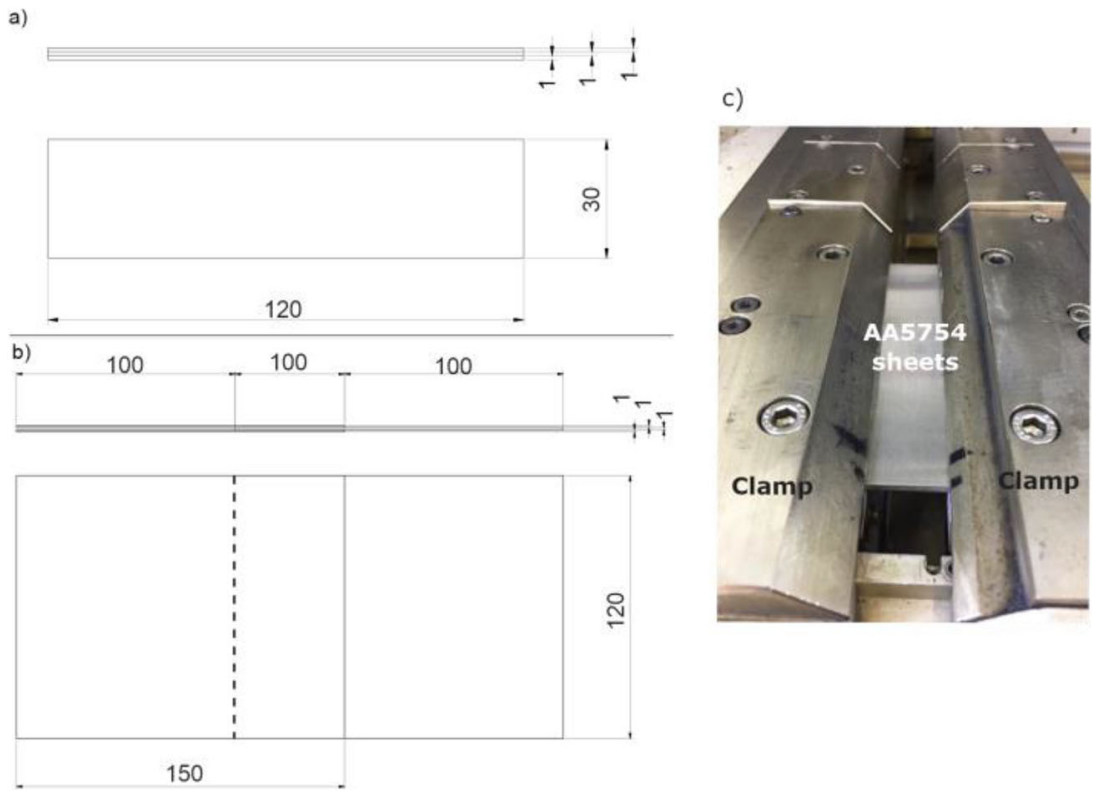

Fig. 4 a Welding sample in double lap-joint for producing weld seam cross-sections. b Double lap-joint welding samples for tensile shear test. $\mathbf{c}$ View of the fixturing system used during the experiments showing the sheets clamped for the weld seam cross-section sample production

to depend on the weld speed, while the effect of the focal position seems limited. Combined with the observations on the weld width, it can be deduced that the focal position has an impact on the shape of the weld seam. It can be concluded that with fixed weld speed the weld seam should have a lower aspect ratio (depth/width) working with a defocused beam.

On the other hand, Fig. 7 also shows that the pore formation appears to be affected mainly by the weld speed. As seen in Fig. 5, the morphology of the pores are commonly irregular and non-spherical, which are common to the keyhole-induced porosity [35]. Hydrogen pores as well as metallurgical pores can form in the absence of the shielding gas, which are much smaller in size and spherical in form. It can be expected that at higher speeds, the keyhole is more instable with a higher inclination towards the back of the melt pool generated during the process $[35,36]$. Moreover, as the weld speed increases, the full penetration is lost. In such conditions, gas entrapment possibility increases as the metallic vapor can only be evacuate towards to upper side of the keyhole, while the bottom end is closed. The effect of the focal position can be attributed to the capacity of maintaining a full penetration condition. As the focal point is moved above the surface of the first layer of the Al-alloy sheets, the beam size on the material surface is enlarged. Hence, the power density is lowered. Maintaining a full penetration condition becomes more difficult at higher weld speeds in combination with higher focal positions.

Figure 8 shows the penetration depth as a function of process parameters. It can be seen that full penetration is maintained between 2.2 and $8.2 \mathrm{~m} / \mathrm{min}$ with $f=0 \mathrm{~mm}$ and $f=-2 \mathrm{~mm}$. On the other hand, full penetration is lost starting from $8.2 \mathrm{~m} / \mathrm{min}$ with $f=-4 \mathrm{~mm}$. It can also be viewed that the penetration depth decays faster as a function of weld speed, when the laser beam is defocused. Especially at higher weld speeds, the seam penetration is unstable and only a partial region is observed to penetrate with limited weld width. Overall, the results show that the process is robust enough to achieve full penetration welds with a variation of $2 \mathrm{~mm}$ of focal point, reaching a reasonable productivity with a welding speed of $8.2 \mathrm{~m} / \mathrm{min}$.

\subsection{Mechanical strength of the welds}

Figure 9 shows the mechanical strength of the two interfaces as a function of process parameters, where a strong relation of the strength of the second interface with the welding speed is visible. It can be seen that the strength of the first interface seems to be less influenced by the process parameters. The strength of the second interface depends on both investigated parameters. This observation is coherent to the effect of the process parameters on the weld penetration and the width at the second interface. Moreover, it is observed that at lower weld speeds the shear strength of the second interface exceeds that of the first one. This can be attributed to the surface undercuts observed in these conditions, weakening the joint.

The mechanical strength at the second interface can be mainly related to the width at the interface. The tensile force follows a similar trend comparable to that of the $w_{\text {int,2. }}$. Indeed, the conditions where the weld was partial and unstable such as those with higher weld speed and $f=-4 \mathrm{~mm}$ the rupture occurs at approximately $1 \mathrm{kN}$ with a larger variability. On the other hand, with lower weld speeds the tensile force at the second interface reaches approximately $4.5 \mathrm{kN}$, where wider seams are present 


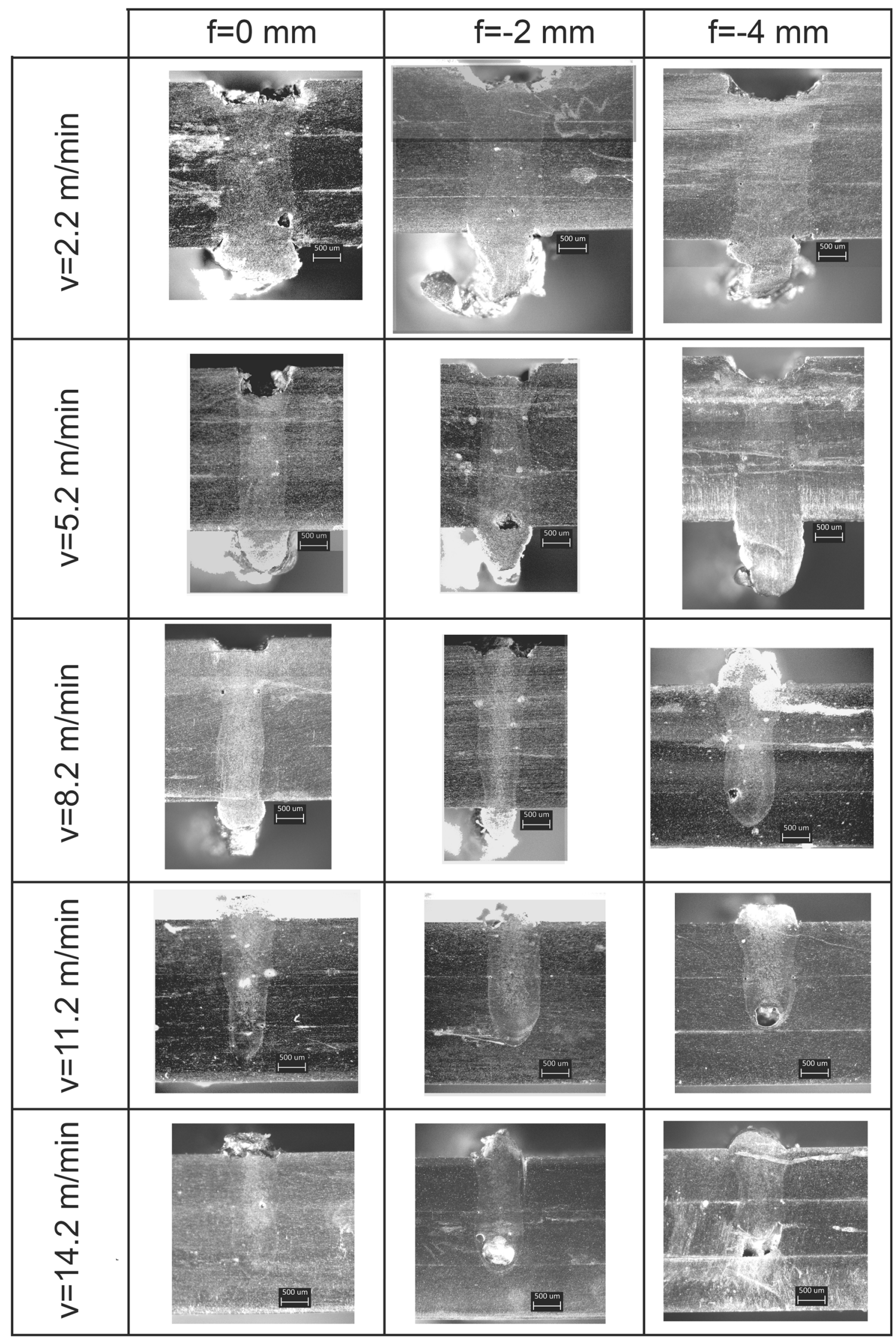

Fig. 5 Cross-section images of the weld seams as a function of the varied process parameters 
Fig. 6 First and second interface widths as a function of the varied process parameters
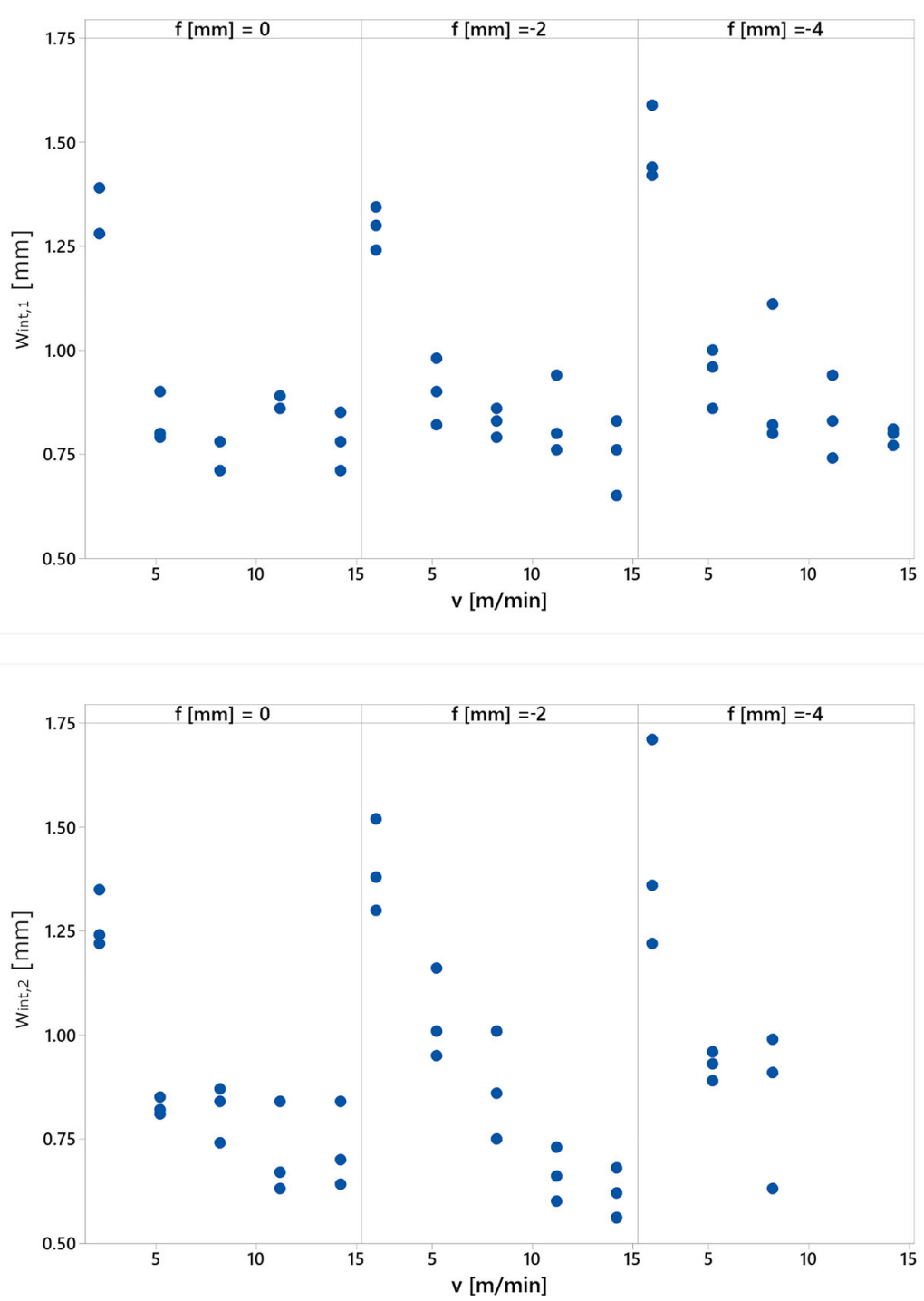

in the second interface. The mechanical strength of the first interface, on the other hand, required further considerations. Indeed, the forces do not follow the exact trend as the seam width at the first interface. It can be noted that the first interface is also closer to the surface, where undercuts are present at low weld speeds, which can intensify the stress locally. Moreover, the excessive material loss at the surface can be a further indication to a more pronounced thermal damage around the first interface. Indeed, the intense vaporization around the upper part of the weld can lead to the loss of the alloying element with lower vaporization namely Mg. Resultantly, with lower weld speeds the heat damage and undercuts prevail against the larger weld width at the first interface, while with higher weld speeds weld width remains in a stable region. The overall mechanical strength at the fist interface remains around $3.5 \mathrm{kN}$. In the second interface higher tensile forces could be observed, which can be attributed to mainly the absence of the effects related to the undercuts.

\subsection{Back reflection signal with respect to process parameters}

Figure 10 shows the mean value of the BR as a function of the process parameters. The value of BR read by the monitoring system is related to the process emission as well as the back reflected laser light. The plasma emission of $\mathrm{Al}$ species corresponds to the UV region, where the photodiode sensitivity is low [37]. On the other hand, owing also to the high reflectivity of the material, the strength of the back reflected laser is expected to be much larger than that of the plume and plasma emission occurring during the process. It can be seen that the signal value grows with the speed and also with the defocusing. Such conditions depict a signal intensity variation mainly due to the back reflected laser light amount. The signal intensity is at its lowest, when full penetration welds with large seam widths are observed. Evidently this means that 
Fig. 7 The weld and pore areas as a function of the varied process parameters

Fig. 8 Penetration depth as a function of the varied process parameters
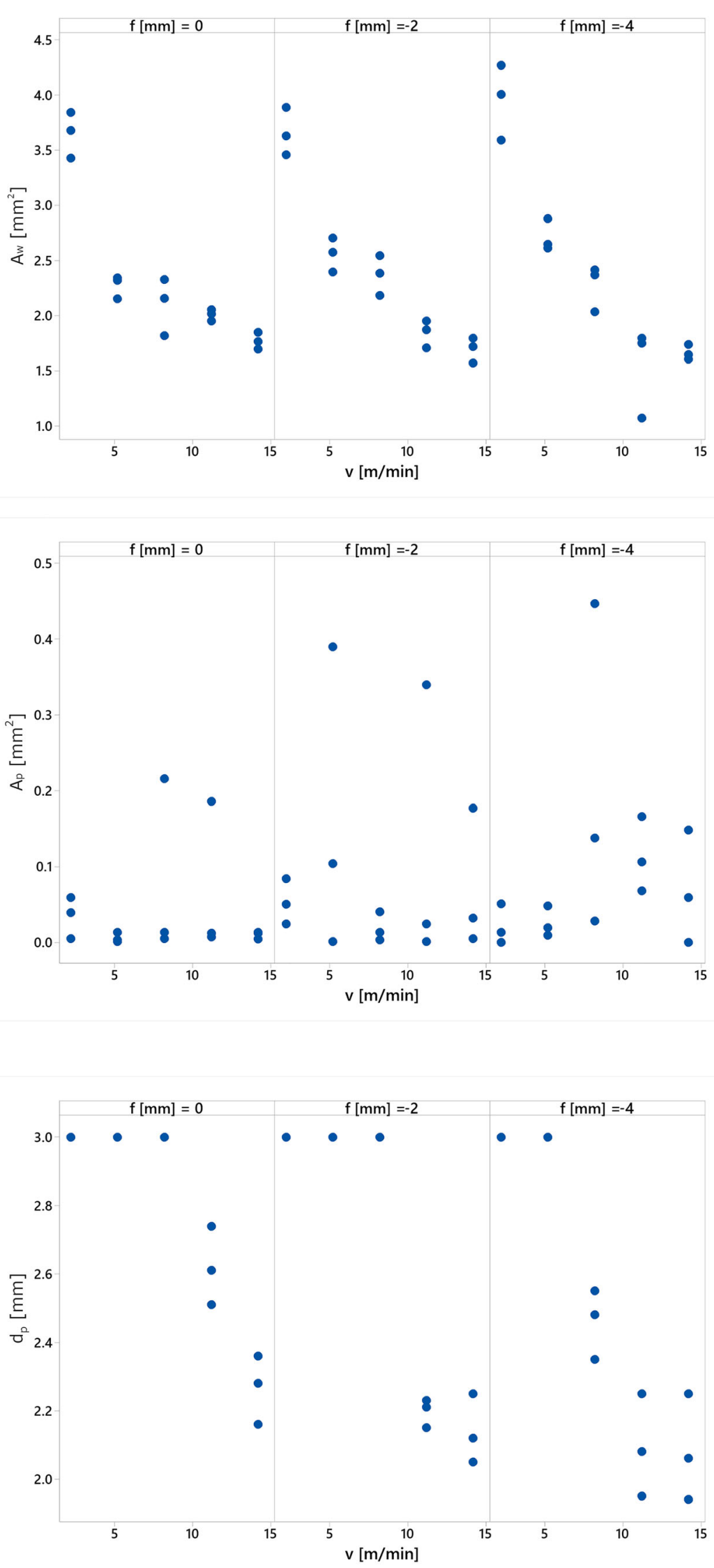
Fig. 9 Mechanical strength at the first and second interfaces as a function of the process parameters

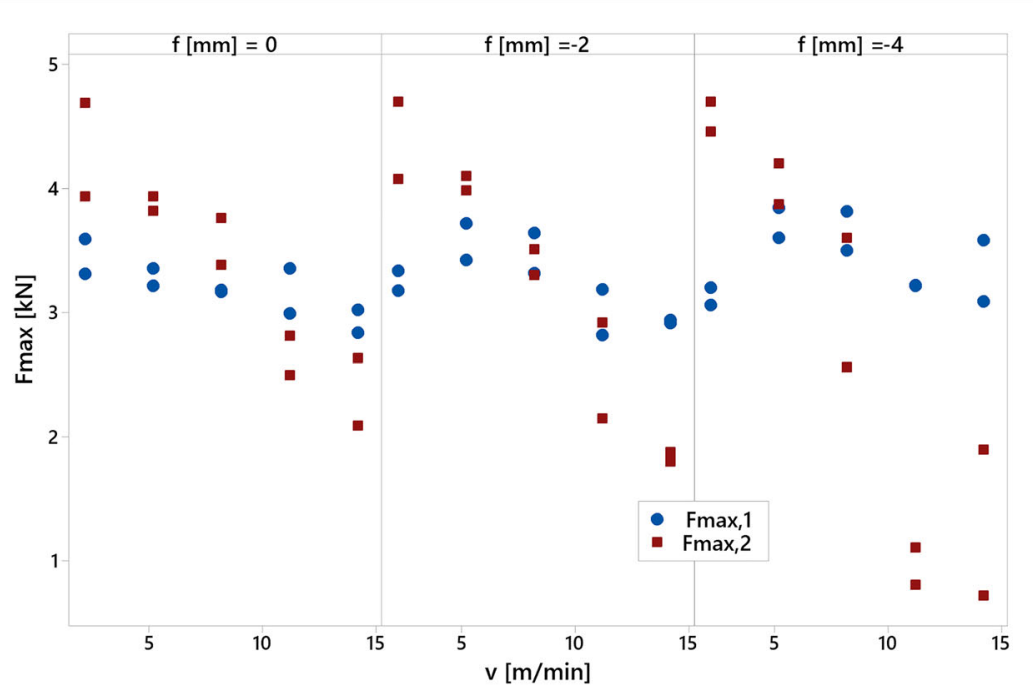

the laser light is mostly absorbed by the material and also partially lost from the open end of the keyhole. At higher speeds, the weld front starts to incline reflecting more laser light towards the laser head [38]. When the penetration at the third sheet is lost, it is expected to act as a fully reflective front sending a large amount of laser back perpendicular to the material surface. Hence, the BR signal values reach the highest in these conditions.

\subsection{Correlation of monitoring signal intensity to the geometrical characteristics}

In order to assess the feasibility of using the monitoring signal to assess the weld quality, correlations between the weld geometry and the signal intensity were sought. The measured geometric features are plotted with respect to the mean value of the BR signal in Fig. 11. The welds were also categorically classified in terms of the penetration namely full penetration at low speed with excessive melting, full penetration, partial penetration up to the third layer, and lack of penetration in the third layer. The classification was carried out by visual inspection of the welded samples prior to the preparation of the cross sections. A high amount of drop-out formation was assessed as full penetration at low speed with excessive melting. Weld seams with a visible penetration on the bottom side without excessive drop-out were tagged as full penetration. Welds, which remained intact without a visible seam on the bottom sides, were categorized as partial penetration. The lack of penetration corresponded to the samples, which would partially delaminate in the second interface by a minimum force
Fig. 10 Mean BR intensity as a function of the varied process parameters

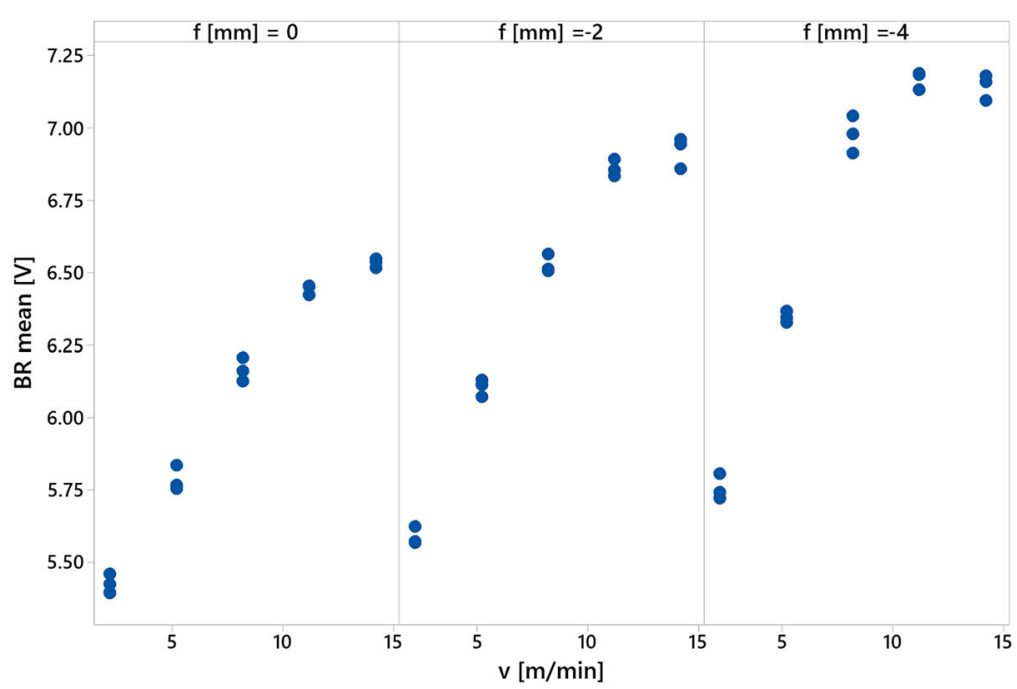


applied. From the plots, it can be seen that the BR value can approximately distinguish between weld categories, especially the excessive melting condition against the others. In Fig. 11a a weak correlation between the BR value and the width at the first interface is viewed. Considering the width at the second interface the correlation with BR appears to be stronger as seen in Fig. 11b, while this indicator could not show the lack of penetration conditions. As seen in Fig. 11c a clear trend between the BR values and the weld area is visible. Evidently, as the amount of material molten during the process decreases, more laser light is back reflected to the sensor. On the other hand, weld penetration could not be easily correlated to the BR intensity. As a matter of fact, the weld conditions with complete penetration were observed in a large range of BR intensity levels. It can be seen in Fig. 11d that the several lack of penetration conditions generated $d_{p}$ values higher than $2 \mathrm{~mm}$. The measured penetrations refer to the maximum penetrations observed locally without producing sufficiently large weld width at the interface. Indeed, due to the low stability of the process in these conditions, the penetration varies without sufficient bonding in the second interface.

\subsection{Correlation of signal intensity to the mechanical strength}

The correlation of the signal intensity to the mechanical strength can allow to assess the strength of a weld by an online monitoring system. Figure 12 shows the strength of the first and second interfaces as against the BR signal intensity. It can be seen that the strength of the first interface varies in a large interval independently from the BR level. Indeed, the strength of the first interface did not show significant variations as a function of the process parameters either. On the other hand, a clear correlation between the strength of the second interface and the BR intensity can be seen. Its relation is looked for with a regression. A second-order regression equation could be fitted to the experimental data in order to predict the strength at the second interface. The model fitted the data adequately as observed by the high level of $R^{2}$ adj at $97.44 \%$.

$$
F_{\max 2}=2.916 B R-0.3746 B R^{2}[k N]
$$
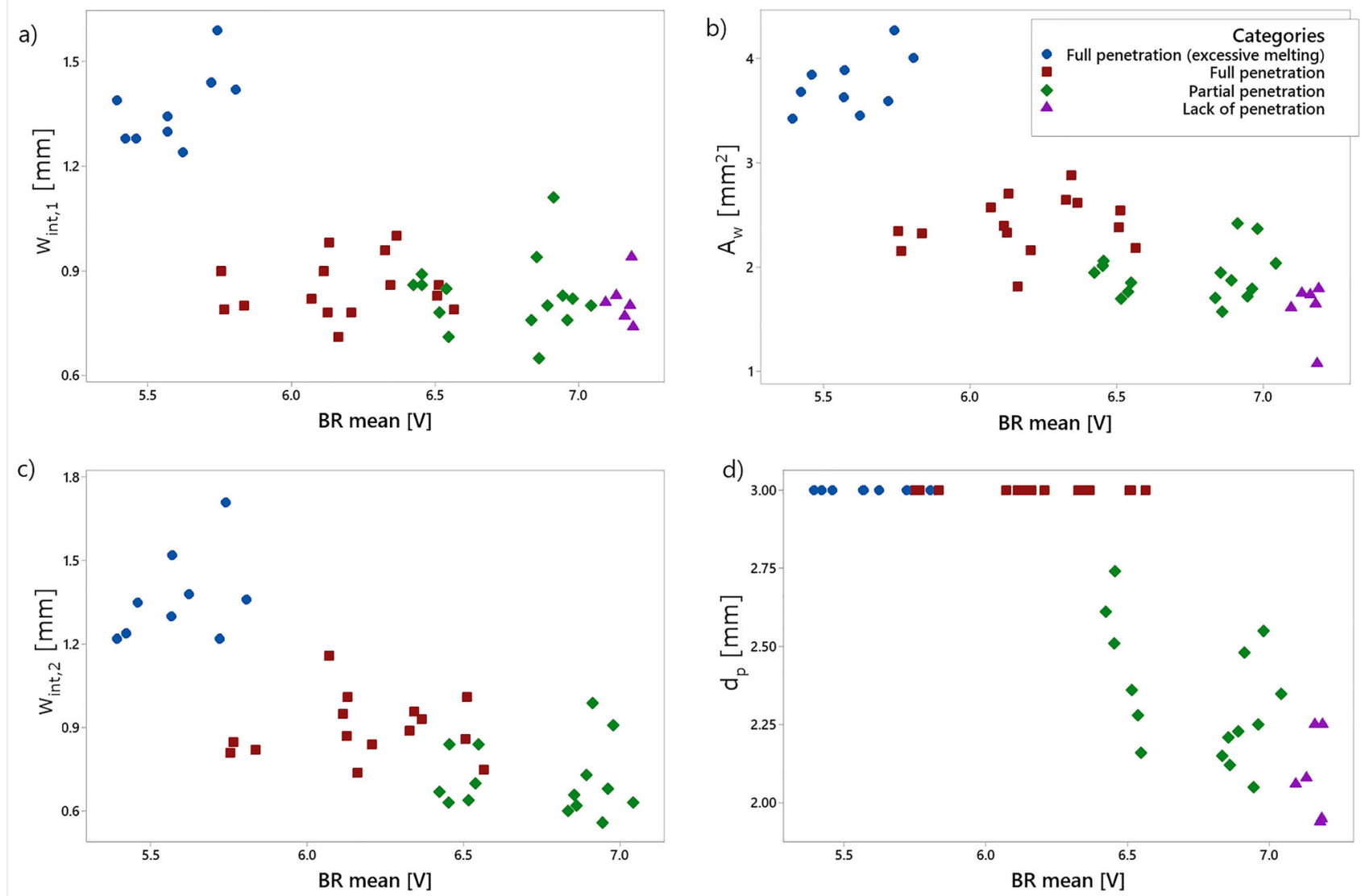

Fig. 11 Back reflection signal intensity vs weld geometry indicators grouped by the qualitative weld categories. a Width at the first interface, $\mathbf{b}$ seam area, $\mathbf{c}$ width at the second interface, and $\mathbf{d}$ penetration depth 


\section{Monitoring of the simulated weld defects}

The monitoring system was also evaluated to detect process anomalies with respect to the stable welding conditions. A preliminary examination of these operations was developed choosing as reference condition the most productive condition allowing a full penetration. Hence, the welding speed was fixed at $8.2 \mathrm{~m} / \mathrm{min}$ and the focal position at $0 \mathrm{~mm}$. Starting from this condition, different types of anomalies in the industrial production were simulated to view the signal variations. The simulated weld defects were as follows.

- Decrease in laser power that can happen due to the wearing of optics. The weld was carried out by reducing the power to $2.5 \mathrm{~kW}$.

- Focus position shift due to wrong fixing of the workpiece. Wrong fixing of the workpiece can lead to a wrong focal position thus to a bad process condition. In order to investigate this weld defect, the double lap joint stack was inclined in order to have a focus shift from 0 to $-10 \mathrm{~mm}$ with respect to the top surface (see Fig. 13a).

- Presence of gap between layers. Faulty fixing and dimensional variations of the welded material can be a cause of the presence of gap between the layers. In this case the weld can suffer of lack of penetration or lack of joint. The sample in this case presents an increasing gap between first and second layer that goes from 0 to $5 \mathrm{~mm}$ (see Fig. 13b).

A focal position variation of $-10 \mathrm{~mm}$ and a gap of $5 \mathrm{~mm}$ are over the general tolerance limits of fixturing systems. However, they were employed to acquire signals in a larger region for both dimensions. The weld track length was $100 \mathrm{~mm}$ for stable process and power decrease conditions.
The focal shift was applied along $110 \mathrm{~mm}$, while the gap between layers required a longer tack of $140 \mathrm{~mm}$.

Figure 14 shows the BR signals with the simulated weld defects compared with the stable process conditions. It can be noted that all the signals are approximately $0.4 \mathrm{~s}$ longer than the nominal duration, due to the initial acceleration and final deceleration zones along the trajectory. As a matter of fact, all signals show an increasing trend in the beginning and a decreasing trend at the end due to the change of weld speed. In the case of power decrease, it can be seen that the signal has the same shape of the reference one but the mean value is clearly smaller. The signal belonging to the focus position shift shows an increase in the signal intensity and variability. Both signal characteristics imply a higher back refection due to the loss of penetration. Concerning the gap between layers, it can be seen that the gap presence starts a large fluctuation in the signal intensity. The process stability appears to be lost despite mean of the signal remaining in the reference band. Overall, the results show that in addition to the signaling of the weld defect, the signal form and intensity can be further studied in more detail to indicate the defect cause.

\section{Conclusions}

This work investigated the laser welding of AA5754 alloy in a double lap-joint configuration concerning the weld geometry, strength, as well as its process monitoring. The process monitoring approach was based on the measurement of the back reflected light from the process via an integrated photodiode in the laser source. The double-lap joint welding was investigated as a function of weld speed and focal position, achieving a large range of weld seam geometries and monitoring signals. The main outcomes of the work are as follows.
Fig. 12 Maximum load as a function of the BR mean intensity grouped by stressed interfaces. The dashed line refers to the regression curve of the maximum load of the second interface as a function of the BR mean intensity

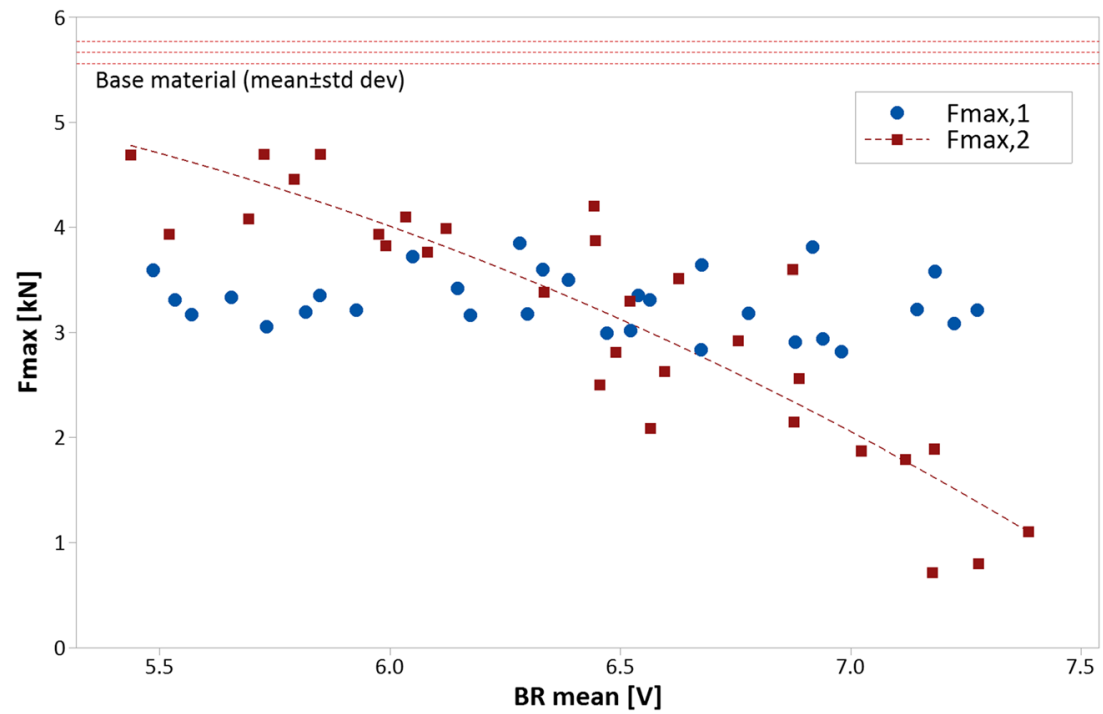


Fig. 13 Schematic representation of the simulated weld defects. a Focal position shift. b Increasing gap

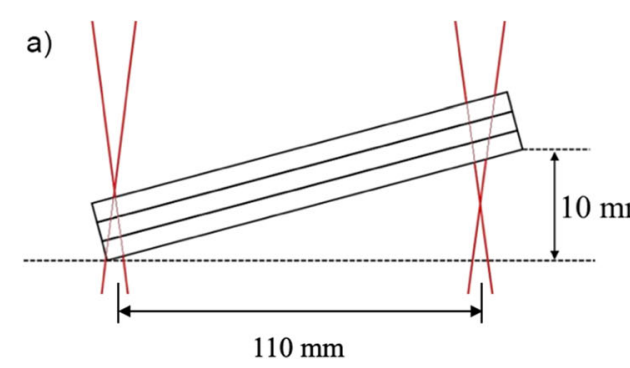

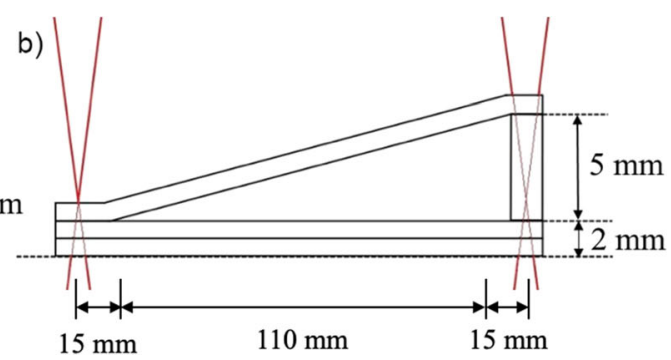

- Full penetration welds can be achieved at high productivity up to $8.2 \mathrm{~m} / \mathrm{min}$ with a laser power of $3 \mathrm{~kW}$. At lower weld speeds excessive drop-out and surface undercuts occur. It was seen that having the focal position at the surface of the first plate is favorable to maintain full penetration by maintaining high energy density and keeping the keyhole open. For maintaining stable welding conditions for the automotive application, where full penetration is desired also as an aid to the visual inspection, a welding speed at $8.2 \mathrm{~m} / \mathrm{min}$ and focal position at the surface of the first plate $(f=0 \mathrm{~mm})$ are appropriate.

- The process parameters were found to have a stronger effect on the maximum shear force at the second interface, while the maximum shear force at the first interface did

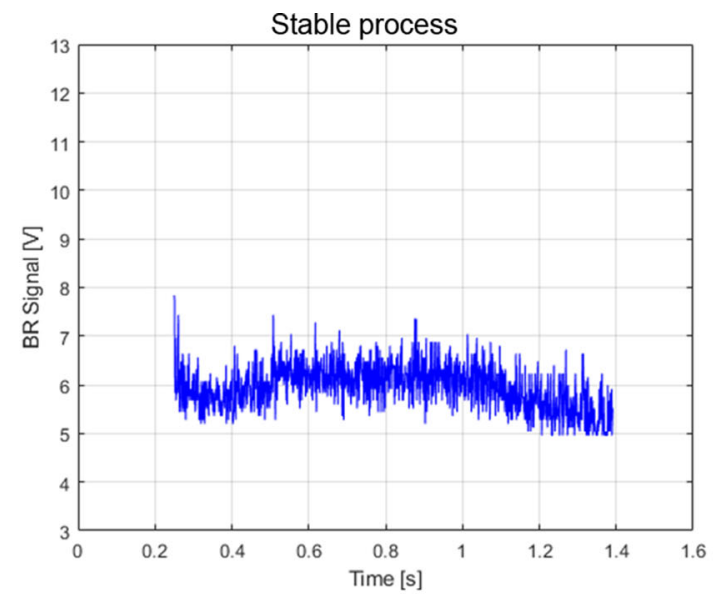

Focus position shift

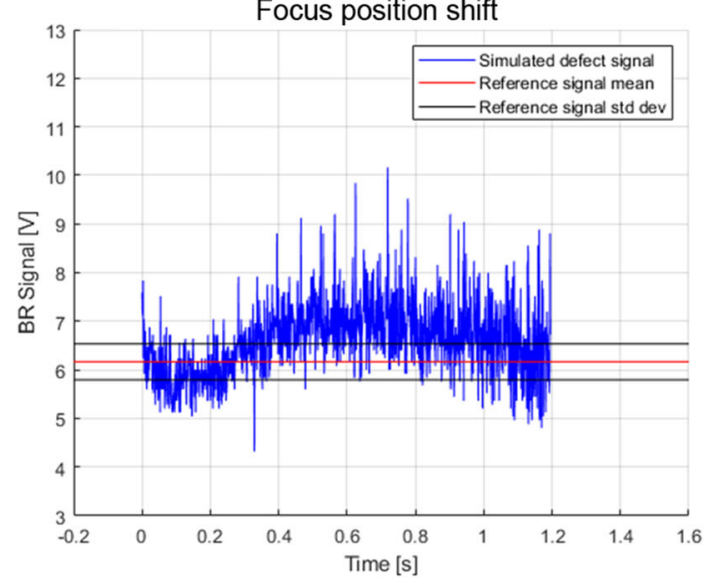

not show a relevant change as a function of the process parameters. Indeed, this is related to achieving full or partial penetration conditions ensuring the strength of the joint at the second interface.

- The back reflected light signal intensity is strictly correlated to the weld area, which is indicative of the efficacy of the process in terms of melting the highly reflective Alalloy. A reduction in the signal intensity shows a more stable weld characterized by full penetration and sufficient width at the second interface.

- The weld strength at the second interface, which is the most critical one as observed in the experiments, could be directly correlated to the back reflected signal intensity.
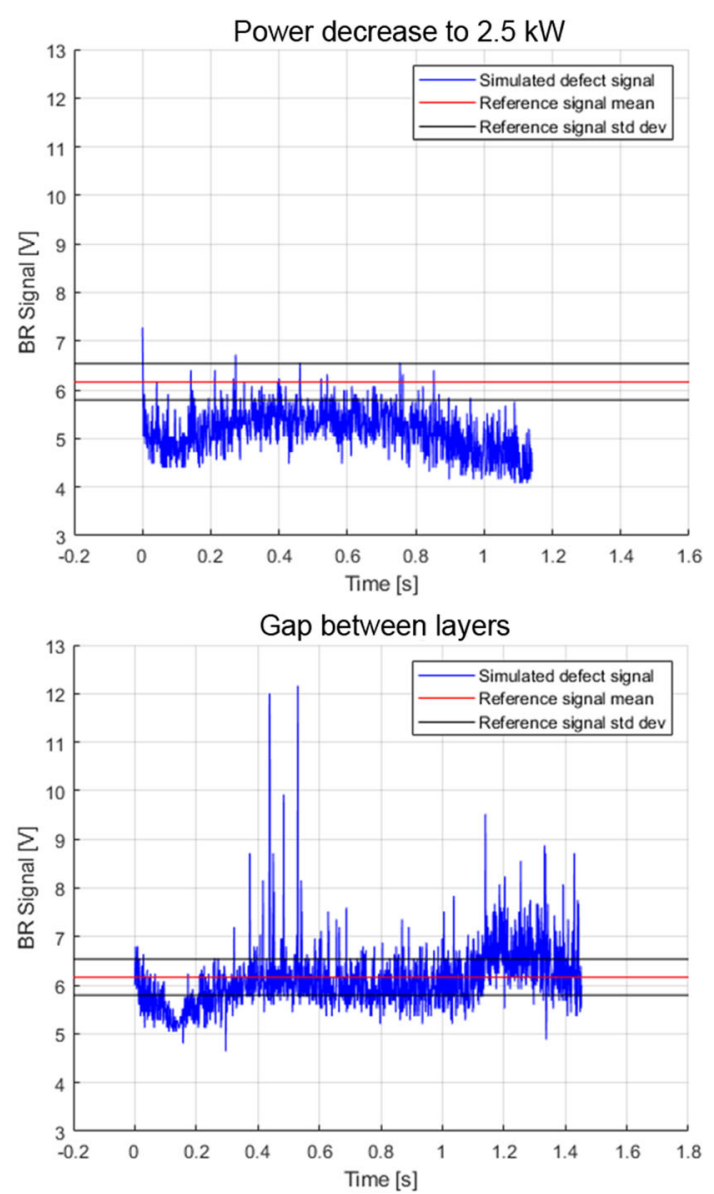

Fig. 14 BR signal in stable welding condition compared with the simulated weld defect types 
- Defected welding conditions were simulated and compared with the stable welding conditions. In all conditions signal intensity deviated from the stable signal intensity region. Although such analysis is simple in its nature, it is promising for further industrialization through more sophisticated signal analysis techniques.

Acknowledgments The Italian Ministry of Education, University and Research is acknowledged for the support provided through the Project "Department of Excellence LIS4.0 - Lightweight and Smart Structures for Industry 4.0 ".

Funding Open access funding provided by Politecnico di Milano within the CRUI-CARE Agreement.

Open Access This article is licensed under a Creative Commons Attribution 4.0 International License, which permits use, sharing, adaptation, distribution and reproduction in any medium or format, as long as you give appropriate credit to the original author(s) and the source, provide a link to the Creative Commons licence, and indicate if changes were made. The images or other third party material in this article are included in the article's Creative Commons licence, unless indicated otherwise in a credit line to the material. If material is not included in the article's Creative Commons licence and your intended use is not permitted by statutory regulation or exceeds the permitted use, you will need to obtain permission directly from the copyright holder. To view a copy of this licence, visit http://creativecommons.org/licenses/by/4.0/.

\section{References}

1. Hong KM, Shin YC (2017) Prospects of laser welding technology in the automotive industry: a review. J Mater Process Technol 245: 46-69. https://doi.org/10.1016/j.jmatprotec.2017.02.008

2. Brand MJ, Schmidt PA, Zaeh MF, Jossen A (2015) Welding techniques for battery cells and resulting electrical contact resistances. J Energy Storage 1:7-14. https://doi.org/10.1016/j.est.2015.04.001

3. Chen S, Zhai Z, Huang J, Zhao X, Xiong J (2016) Interface microstructure and fracture behavior of single/dual-beam laser welded steel-Al dissimilar joint produced with copper interlayer. Int $\mathrm{J}$ Adv Manuf Technol 82:631-643. https://doi.org/10.1007/s00170015-7390-x

4. De Bono P, Blackburn J Laser welding of copper and aluminium battery interconnections. Ind Laser Appl Symp (ILAS 2015) 9657(2015):96570M. https://doi.org/10.1117/12.2176048

5. Kah P, Vimalraj C, Martikainen J, Suoranta R (2015) Factors influencing $\mathrm{Al}-\mathrm{Cu}$ weld properties by intermetallic compound formation. Int J Mech Mater Eng 10. https://doi.org/10.1186/s40712015-0037-8

6. Coroado J, Meco S, Williams S, Ganguly S, Suder W, Quintino L, Assunção E (2017) Fundamental understanding of the interaction of continuous wave laser with aluminium. Int J Adv Manuf Technol 93:3165-3174. https://doi.org/10.1007/s00170-017-0702-6

7. Quintino L, Costa A, Miranda R, Yapp D, Kumar V, Kong CJ (2007) Welding with high power fiber lasers - a preliminary study. Mater Des 28:1231-1237. https://doi.org/10.1016/j.matdes.2006. 01.009

8. Yu Y, Wang C, Hu X, Wang J, Yu S (2010) Porosity in fiber laser formation of 5A06 aluminum alloy. J Mech Sci Technol 24:10771082. https://doi.org/10.1007/s12206-010-0309-4

9. Huang L, Hua X, Wu D, Li F (2018) Numerical study of keyhole instability and porosity formation mechanism in laser welding of aluminum alloy and steel. J Mater Process Technol 252:421-431. https://doi.org/10.1016/j.jmatprotec.2017.10.011

10. Cao X, Wallace W, Poon C, Immarigeon JP Research and progress in laser welding of wrought aluminum alloys. I Laser welding processes, Mater Manuf Process 18(2003):1-22. https://doi.org/10. 1081/AMP-120017586

11. Wang X, Lu F, Wang HP, Cui H, Tang X, Wu Y (2015) Mechanical constraint intensity effects on solidification cracking during laser welding of aluminum alloys. J Mater Process Technol 218:62-70. https://doi.org/10.1016/j.jmatprotec.2014.11. 037

12. Langrieger H, Krafft F, Mensinger M, Oefele F (2016) Thermomechanical analysis of the formation of hot cracks in remote laser welded aluminium fillet welds. J Laser Appl 28:022414. https://doi.org/10.2351/1.4944093

13. Pellone L, Inamke G, Hong KM, Shin YC (2019) Effects of interface gap and shielding gas on the quality of alloy AA6061 fiber laser lap weldings. J Mater Process Technol 268:201-212. https:// doi.org/10.1016/j.jmatprotec.2019.01.025

14. Franciosa P, Serino A, Al Botros R, Ceglarek D (2019) Closed-loop gap bridging control for remote laser welding of aluminum components based on first principle energy and mass balance. J Laser Appl 31:022416. https://doi.org/10.2351/1.5096099

15. Li Y, Zhang Y, Luo Z, Shan H, Feng YQ, Ling ZX (2016) Failure mode transition of triple-thin-sheet aluminum alloy resistance spot welds under tensile-shear loads. Weld J:95, 479s-490s

16. Hietala M, Hamada A, Keskitalo M, Jaskari M, Järvenpää A (2019) Mechanical characterization of laser-welded double-lap joints in ultra-high and low strength steels for sandwich panel applications. Mater Today Proc 28:2-7. https://doi.org/10.1016/j.matpr.2019.10. 031

17. You DY, Gao XD, Katayama S (2014) Review of laser welding monitoring. Sci Technol Weld Join 19:181-201. https://doi.org/10. 1179/1362171813Y.0000000180

18. Luo Y, Zhu L, Han J, Xie X, Wan R, Zhu Y (2019) Study on the acoustic emission effect of plasma plume in pulsed laser welding. Mech Syst Signal Process 124:715-723. https://doi.org/10.1016/j. ymssp.2019.01.045

19. Huang Y, Xu S, Yang L, Zhao S, Liu Y, Shi Y (2019) Defect detection during laser welding using electrical signals and highspeed photography. J Mater Process Technol 271:394-403. https://doi.org/10.1016/j.jmatprotec.2019.04.022

20. Zhang Y, Zhang N, You D, Gao X, Katayama S (2019) High-power disk laser welding statuses monitoring based on analyses of multiple-sensor signals. J Manuf Process 41:221-230. https://doi. org/10.1016/j.jmapro.2019.03.028

21. Elefante A, Nilsen M, Sikström F, Christiansson AK, Maggipinto T, Ancona A (2019) Detecting beam offsets in laser welding of closed-square-butt joints by wavelet analysis of an optical process signal. Opt Laser Technol 109:178-185. https://doi.org/10.1016/j. optlastec.2018.08.006

22. Shevchik SA, Le-Quang T, Farahani FV, Faivre N, Meylan B, Zanoli S, Wasmer K (2019) Laser welding quality monitoring via graph support vector machine with data adaptive kernel. IEEE Access 7:93108-93122. https://doi.org/10.1109/ACCESS.2019. 2927661

23. Xiao X, Liu X, Cheng M, Song L (2020) Towards monitoring laser welding process via a coaxial pyrometer. J Mater Process Technol 277:116409. https://doi.org/10.1016/j.jmatprotec.2019.116409

24. Chen Y, Chen B, Yao Y, Tan C, Feng J (2019) A spectroscopic method based on support vector machine and artificial neural network for fiber laser welding defects detection and classification. NDT E Int 108:102176. https://doi.org/10.1016/j.ndteint.2019. 102176

25. Boley M, Fetzer F, Weber R, Graf T (2019) Statistical evaluation method to determine the laser welding depth by optical coherence 
tomography. Opt Lasers Eng 119:56-64. https://doi.org/10.1016/j. optlaseng.2019.03.014

26. Mittelstädt C, Mattulat T, Seefeld T, Kogel-Hollacher M (2019) Novel approach for weld depth determination using optical coherence tomography measurement in laser deep penetration welding of aluminum and steel. J Laser Appl 31:022007. https://doi.org/10. 2351/1.5082263

27. Kim CH, Ahn DC (2012) Coaxial monitoring of keyhole during Yb:YAG laser welding. Opt Laser Technol 44:1874-1880. https:// doi.org/10.1016/j.optlastec.2012.02.025

28. Schaumberger K, Beck M, Saffer J, Kaufmann F, Ermer J, Roth S, Schmidt M (2019) Improving process reliability by means of detection of weld seam irregularities in copper via thermographic process monitoring. Procedia Manuf 36:58-63. https://doi.org/10.1016/j. promfg.2019.08.009

29. Staudt T, Eschner E, Schmidt M (2019) Temperature determination in laser welding based upon a hyperspectral imaging technique. CIRP Ann 68:225-228. https://doi.org/10.1016/j.cirp.2019.04.117

30. Colombo D, Colosimo BM, Previtali B (2013) Comparison of methods for data analysis in the remote monitoring of remote laser welding. Opt Lasers Eng 51:34-46. https://doi.org/10.1016/j. optlaseng.2012.07.022

31. Garavaglia M, Demir AG, Zarini S, Victor BM, Previtali B (2019) Process development and coaxial sensing in fiber laser welding of 5754 Al-alloy. J Laser Appl 31:022419. https://doi.org/10.2351/1. 5096101

32. Demir AG, De Giorgi C, Previtali B (2017) Design and implementation of a multi-sensor coaxial monitoring system with correction strategies for selective laser melting of a maraging steel. J Manuf Sci Eng 140:1-14. https://doi.org/10.1115/1.4038568

33. Ramasamy S, Albright CE (2001) CO2 and Nd-YAG laser beam welding of 5754-O aluminium alloy for automotive applications. Sci Technol Weld Join 6:182-190. https://doi.org/10.1179/ 136217101101538730

34. Kliner DAV (2016) nLIGHT alta TM: a versatile, next-generation fiber laser platform for $\mathrm{kW}$ materials processing, in: 84th Laser Mater. Process. Conf.. https://doi.org/10.1586/erp.10.82

35. Huang L, Hua X, Wu D, Ye Y (2019) Role of welding speed on keyhole-induced porosity formation based on experimental and numerical study in fiber laser welding of Al alloy. Int J Adv Manuf Technol 103:913-925. https://doi.org/10.1007/s00170-019-03502$\mathrm{x}$

36. Xu J, Rong Y, Huang Y, Wang P, Wang C (2018) Keyhole-induced porosity formation during laser welding. J Mater Process Technol 252:720-727. https://doi.org/10.1016/j.jmatprotec.2017.10.038

37. Jasim HA, Demir AG, Previtali B, Taha ZA (2017) Process development and monitoring in stripping of a highly transparent polymeric paint with ns-pulsed fiber laser. Opt Laser Technol 93. https:// doi.org/10.1016/j.optlastec.2017.01.031

38. Fabbro R (2010) Melt pool and keyhole behaviour analysis for deep penetration laser welding. J Phys D Appl Phys 43. https://doi.org/ $10.1088 / 0022-3727 / 43 / 44 / 445501$

Publisher's note Springer Nature remains neutral with regard to jurisdictional claims in published maps and institutional affiliations. 